\title{
A POESIA DOS LIVROS E DOS JORNAIS. GUERRA, ESCRITA E METÁFORAS SOCIAIS EM "CARTA A STALINGRADO”, DE DRUMMOND
}

\author{
Ivana Rebello*
}

\begin{abstract}
Resumo: Este artigo reflete sobre o poema "Carta a Stalingrado", de Carlos Drummond de Andrade, e suas relações com as transformações sociais advindas do tempo de guerra. A batalha de Stalingrado, signo de resistência soviética contra o poder nazista, chega ao poeta por meio das notícias de jornais, mas é traduzida, em sua poética, como signo da nova ordem social e da poética da vida moderna.
\end{abstract}

Palavras-chave: Drummond; Carta a Stalingrado; guerra; poesia.

Abstract: This article reflects on the poem "Letter to Stalingrad" by Carlos Drummond de Andrade, and their relations with the social changes resulting from the time of war. The battle of Stalingrad, sign of Soviet resistance against the Nazi power, is translated in his poetics, as a sign of the new social order and the poetics of modern life.

Keywords: Drummond; Letter to Stalingrad; war; poetry.

* Universidade Estadual de Montes Claros. 
Todos os homens voltam para casa.

Estão menos livres mas levam jornais

e soletram o mundo, sabendo que o perdem.

(ANDRADE, 1987, p. 13)

O que é um contexto datado quando subtraído à memória e à consciência presente que o interroga e ilumina? É o que nos pergunta, no último prefácio de seu livro O ser e o tempo da poesia, Alfredo Bosi (2000). Em tal prefácio, Bosi afirma que, no tocante às relações do poema com os tempos da sociedade, importa trazer à luz da consciência as respostas, a maior parte delas tensas, que a obra poética dá às ideologias de cada época e lugar. Como estrutura singular e inventiva de significações, a poesia é tecida de fios resistentes e complexos que fazem dos acontecimentos sua matéria, permitindo-lhes, entretanto, que sejam lidos com os olhos de hoje ou os de amanhã.

É esse o mote inicial de que faço uso para justificar a leitura de um poema aparentemente fincado em sua contextualização histórica, e, portanto, à primeira vista, encerrado em sua contingência imediata. Há pelo menos duas hipóteses para trazer de volta o poema "Carta a Stalingrado", de Carlos Drummond de Andrade, ao centro dessas discussões. A primeira é seu caráter testemunhal, único, capaz de extrair do fato uma experiência invulgar, que condensa as tensões e perplexidades humanas em ritmos e figurações muito específicos. A segunda é que, sendo obra poética, sua datação obedece a uma ordem dialética, que cinde o imediatismo do acontecimento ao lume da consciência artística, cujos efeitos expandem-se para além da cronologia e do documental. Em se tratando de um poeta como Drummond, cuja escrita espelha, como poucas, o embate entre o ser e estar no mundo e o escrever, a letra se prolonga para muito adiante do seu tempo, indo reverberar, com seu caráter de impermanência, na mente inquieta de cada leitor. Posto que muito estudado e discutido, Drummond ainda mantém aquela nota surpreendente que deixa seus textos suspensos no tempo, conhecidos em demasia, sem, no entanto, ficarem velhos. 
"Carta a Stalingrado" foi publicado no livro A rosa do povo, considerado uma das melhores produções de Drummond, com poemas escritos entre 1943 e 1945 . Constituído de 55 poemas, $A$ rosa do povo é também o livro mais extenso do poeta, além de ser, incontestavelmente, a obra que melhor condensa seu lirismo social. Tal lirismo, sempre comedido, tímido, cerebralmente sopesado, será bastante evidente nos versos de "Carrego Comigo", "Movimento da Espada", "O Medo", "A Flor e a Náusea", "Nosso Tempo", "Áporo", "Noite na Repartição", "Visão 1944" e "Telegrama de Moscou". Embora ali encontremos várias facetas da poesia drummondiana, o que se destaca é o forte acento social que ele imprime em seus versos, em cujas linhas se destacam as sombras da Segunda Guerra Mundial e o cenário de horror, medo e angústia que se projeta no mundo em crise.

Fernando Achar situa a obra como representação do ápice do movimento modernista, conforme se verifica a seguir:

Nessa segunda etapa do movimento modernista - que vai, grosso modo, de 1930 a 1945 -, desenvolvem-se na poesia algumas das características mais marcantes de seu primeiro tempo (inovações rítmicas, humor, paródia, temas cotidianos, linguagem coloquial, elipses e associações surpreendentes), ao mesmo tempo que se amplia a temática e se diversificam os recursos e as tendências estilísticas. Esboça-se então o perfil contemporâneo da literatura brasileira, que, como a literatura internacional, testemunha a emergência de três sistemas explicativos do homem e da sociedade: 0 existencialismo, a psicanálise e o marxismo. (ACHCAR, 2000, p. 12-13).

Alfredo Bossi, ao mencionar a evolução da poesia drummondiana, situa o escritor como o primeiro grande poeta que se firmou após as estreias modernistas, apontando A rosa do povo como fruto de uma fase em que o escritor vivia intensamente, sob efeito de um mundo abalado pela guerra. 
O Drummond "poeta público" da Rosa do Povo foi a fase intensa, mas breve, de uma esperança que nasceu sob a Resistência do mundo livre à fúria nazi-facista, mas que logo se retraiu com o advento da Guerra Fria. A civilização que se forma sob os nossos olhos, fortemente amarrada ao neocapitalismo, à tecnocracia, às ditaduras de toda sorte, ressoou dura e secamente no eu artístico do último Drummond, que volta, com frequência, à aridez desenganada dos primeiros versos. (BOSI, 2006, p. 441).

A Segunda Guerra durou oficialmente de 1939 a 1945 , tempo que registrou alguns marcos assustadores. Quase todos os países do globo envolveram-se, de forma mais ou menos efetiva, com as ações bélicas, mobilizando um contingente militar de 100 milhões de homens e cerca de 60 milhões de pessoas, entre civis e soldados, morreram; e 6 milhões de judeus foram exterminados, naquele que foi conhecido como o pior genocídio da história da humanidade.

A data de escrita dos textos de A rosa do povo revela que, nesse tempo, os exércitos nazistas recuavam, sobretudo devido à resistência imposta pelas forças da extinta União Soviética. Drummond, como parte da intelectualidade brasileira da época, manifestava pelos soviéticos uma espécie de reverência comovida, acreditando que o movimento social-esquerdista seria a resposta à barbárie hitlerista, ao descontrole capitalista e à ausência de liberdade.

É preciso ainda ressaltar que o Brasil, na época, vivia o Estado Novo - autoritário e policialesco - de Getúlio Vargas. Desde o início da Segunda Guerra Mundial, a ideologia do Estado Novo, implantado por Getúlio Vargas, apontava para um provável alinhamento do Brasil com os países do Pacto de Aço - Alemanha e Itália. A ditadura implantada por Vargas, em 1937, apoiava-se em uma Constituição centralizadora e autoritária, que guardava muitos pontos em comum com as ditaduras fascistas. O governo Vargas fechou o Congresso, impôs a censura à imprensa, prendeu líderes políticos e sindicais e colocou interventores nos governos 
estaduais. Com um estilo populista, Getúlio Vargas montou um poderoso esquema de propaganda pessoal ao criar o Departamento de Imprensa e Propaganda (DIP), claramente inspirado no aparelho nazista de propaganda idealizado por Joseph Goebbels. "A Hora do Brasil", introduzida nas rádios brasileiras e chamada ironicamente pela intelectualidade de "Fala Sozinho", mostrava os feitos do governo, escondendo a repressão política praticada contra uma sociedade pouco organizada na época. Entretanto, Vargas criou o salário mínimo e instituiu a Consolidação das Leis do Trabalho (CLT), entre outros benefícios sociais, o que o levou a ser aclamado como "pai dos pobres" pela população de baixa renda. Havia, pois, uma confusa mistura de tendências nazifascistas e populistas que ressoava no Brasil como efeito político direto da guerra que dizimava a Europa e impingia ao povo uma sensação de desamparo e insegurança.

Em A rosa do povo tais contingências se fazem sentir por meio de uma permanente tensão entre a participação política (muito comedida em Drummond), a adesão às ideias esquerdistas, de um lado, e o tom desencantado, do outro. Em mais da metade dos poemas do livro lê-se uma angústia persistente, que se apega ao engajamento e ao compromisso com a humanidade. Neles se encontram refletidas a culpa e a responsabilidade moral, o registro de uma ordem política injusta, a progressão de um estado de náusea para uma mudança de perspectivas e a esperança de uma nova ordem política. Tais características podem, de certa forma, ilustrar o paradoxo do intelectual com tendências esquerdistas que também servia ao governo.

Como se sabe, Drummond foi chefe de gabinete do ministro da Educação, Gustavo Capanema, de 1934 a 1945, o que compreende o período de duração de toda a Segunda Guerra Mundial. Segundo ele próprio, era funcionário público para seu sustento, cronista por obrigação e poeta por vocação. Somente em 1945, findada a guerra, é que o poeta desliga-se da função no Ministério da Educação e vive breve experiência no Partido 
Comunista, embora a ele nunca tenha se filiado, de fato. A pedido de Luís Carlos Prestes, Drummond atua como codiretor de um jornal comunista, do qual logo se desliga, por discordar da orientação do jornal. Em A rosa do povo, todas essas contradições parecem somar-se, revelando a tensão permanente do homem no mundo, que o leva a abrir-se a uma solidariedade entre dolorosa e impotente. Um poema exemplar nesse aspecto é "Carrego Comigo", no qual o poeta alude a um misterioso embrulho que traz consigo, sem, no entanto, revelar o que tem em seu conteúdo:

\author{
Carrego comigo \\ há dezenas de anos \\ há centenas de anos \\ o pequeno embrulho. (...) \\ Não ouso entreabri-lo. \\ Que coisa contém, \\ ou se algo contém, \\ nunca saberei.
}

(ANDRADE, 1987, p. 15)

O conflito do sujeito revela-se no jogo que se faz entre o ser que carrega o embrulho e no embrulho que parece carregá-lo, pois perdê-lo significa "perder-me a mim próprio", como confessam os versos finais. A confusão encetada entre o que carrega e é carregado ilustra o imbricado entre o homem e o mundo material, sugerindo que um e outro se comprometem, a ponto de se fundirem. Parcela da crítica especializada dirá que não é muito difícil supor que o embrulho metaforiza o peso da consciência moral do poeta. A angústia da escrita, muitas vezes, reside nesse não saber o que se carrega, mas carregar tal peso corresponde a uma imperiosa necessidade de verbalizar a consciência, opor aos fatos certa verdade, a sua verdade, ou pelo menos, parte dela. Tais sentimentos, muito frequentes na lírica drummondiana, fazemno um legítimo representante da turbulência da vida, na modernidade. 
Davi Arrigucci considera, em artigo publicado originalmente no Estado de São Paulo (2007), e posteriormente publicado no livro O guardador de rebanhos (2010), que "Drummond é o poeta central da experiência moderna brasileira", pois, segundo ele, tudo na obra do poeta mineiro não acontece senão por conflito, por meio do qual se projeta a densidade reflexiva de sua lírica. Por essa razão, para o poeta de Itabira, a poesia é o objeto de uma procura dificultosa. A reflexão, sempre presente em seu verbo, é a mediação necessária para o encontro da poesia. E ainda que, aparentemente, os versos manifestem um raro tom de euforia, lá se lê a técnica precisa que os controlam e mensuram, de modo a exprimir aquele algo mais que fascina os leitores e anima a crítica. É o que ocorre, por exemplo, no poema "Carta a Stalingrado", escolhido para análise e aqui transcrito:

Stalingrado...

Depois de Madri e de Londres, ainda há grandes cidades!

O mundo não acabou, pois que entre as ruínas

outros homens surgem, a face negra de pó e de pólvora,

e o hálito selvagem da liberdade

dilata os seus peitos, Stalingrado,

seus peitos que estalam e caem,

enquanto outros, vingadores, se elevam.

A poesia fugiu dos livros, agora está nos jornais.

Os telegramas de Moscou repetem Homero.

Mas Homero é velho. Os telegramas cantam um mundo novo que nós, na escuridão, ignorávamos.

Fomos encontrá-lo em ti, cidade destruída, na paz de tuas ruas mortas mas não conformadas, no teu arquejo de vida mais forte que o estouro das bombas, na tua fria vontade de resistir.

Saber que resistes.

Que enquanto dormimos, comemos e trabalhamos, resistes. Que quando abrimos o jornal pela manhã teu nome (em ouro oculto) estará firme no alto da página. 
Terá custado milhares de homens, tanques e aviões, mas valeu a pena.

Saber que vigias, Stalingrado, sobre nossas cabeças, nossas prevenções e nossos confusos pensamentos distantes

dá um enorme alento à alma desesperada e ao coração que duvida.

Stalingrado, miserável monte de escombros, entretanto resplandecente!

As belas cidades do mundo contemplam-te em pasmo e silêncio. Débeis em face do teu pavoroso poder, mesquinhas no seu esplendor de mármores salvos e rios não profanados, as pobres e prudentes cidades, outrora gloriosas, entregues sem luta, aprendem contigo o gesto de fogo. Também elas podem esperar.

Stalingrado, quantas esperanças!

Que flores, que cristais e músicas o teu nome nos derrama! Que felicidade brota de tuas casas!

De umas apenas resta a escada cheia de corpos;

de outras o cano de gás, a torneira, uma bacia de criança. Não há mais livros para ler nem teatros funcionando nem trabalho nas fábricas, todos morreram, estropiaram-se, os últimos defendem pedaços negros de parede, mas a vida em ti é prodigiosa e pulula como insetos ao sol, ó minha louca Stalingrado!

A tamanha distância procuro, indago, cheiro destroços sangrentos, apalpo as formas desmanteladas de teu corpo, caminho solitariamente em tuas ruas onde há mãos soltas e relógios partidos, sinto-te como uma criatura humana, e que és tu, Stalingrado, senão isto?

Uma criatura que não quer morrer e combate, contra o céu, a água, o metal, a criatura combate, 
contra milhões de braços e engenhos mecânicos a criatura combate,

contra o frio, a fome, a noite, contra a morte a criatura combate,

e vence.

As cidades podem vencer, Stalingrado!

Penso na vitória das cidades, que por enquanto é apenas uma fumaça subindo do Volga.

Penso no colar de cidades, que se amarão e se defenderão contra tudo.

Em teu chão calcinado onde apodrecem cadáveres, a grande Cidade de amanhã erguerá a sua Ordem.

(ANDRADE, 1987, p.128-129)

Embora as estrofes e os versos sejam irregulares, mantêmse o equilíbrio denso das palavras e sonoridades. As pausas sintáticas, a força expressiva de alguns verbos e palavras denotam aquele senso de medida raro, que denunciam o apuro estético, a procura da palavra exata. O ritmo é arfante, descontínuo, em que escapa a angústia desenfreada do poeta, uma luta que entrega a seu leitor a inescapável luta que sustenta sua poesia. O coração do poeta bate em compasso com os desacertos do mundo.

Há, no poema, um tom dissonante ao que se costuma ver na poesia de Drummond. Diferentemente da dicção cética e melancólica que estamos acostumados a ver, na escrita do poeta de Itabira, em "Carta a Stalingrado", parece haver uma palavra disposta a persuadir (-se), uma retórica insistente e repetitiva, que muito a aproxima da continuidade da prosa, embora seus recortes respeitem as linhas do verso.

O título remete ao imbricado de gêneros, que, desde o início, dá o tom de contemporaneidade aos versos. Sendo carta, parece explicitamente endereçada ao outro, mas se pressente que o poeta-emissor é ao mesmo tempo seu destinatário. "Carta a Stalingrado" é uma carta endereçada aos resistentes, é uma carta endereçada a si mesmo, ao próprio poeta, que se quer convencer da possibilidade de renovação e da capacidade de sobrevivência 
da poesia, mas também é manifesto, que exorta o outro - como a ele próprio - a sair da escuridão pela crença de um mundo novo.

Lê-se na "Carta..." a luta que se trava entre a tradição, com a qual, afinal, dialoga, e o novo, que, em muitos momentos da sua poética parece debater-se entre uma desconfiança do lirismo, que é particular, e uma procura angustiada do tom e da palavra certa, na qual possa projetar seu sentimento de mundo, que é da ordem do social. Embora mantenha um tom de apelo coletivo, evidente nos verbos no imperativo, o poema-carta deixa entrever a inescapável solidão individual, que, de resto, frequenta todos os seus textos e que se pode ler nos versos: "dá um enorme alento à alma desesperada/ e ao coração que duvida". As contradições presentes no plano do discurso ostentam esse embate do sujeito lírico, que se divide entre um eu em desalento, que confessa sua "alma desesperada" e seu "coração que duvida", e um mundo que parece triunfar, depois da guerra e da morte. Destaque-se, para efeito de exemplificação, o forte efeito do par "aliterativo" pó e pólvora - que tanto pode aludir ao fim com ao início de tudo.

Stalingrado, a cidade antropomorfizada, acena, especialmente, para uma resistência interna - em meio à destruição e às ruínas como o último apelo da identidade pessoal diante das catástrofes contemporâneas. Tal resistência vem da própria experiência, que também é guerra e combate, e emerge da morte, das faces negras de pó e pólvora.

Em seu texto "Teorias do fascismo alemão", Walter Benjamin reflete sobre a guerra:

O que significa ganhar ou perder uma guerra? Nas duas palavras, chama a atenção um sentido duplo. O primeiro, o sentido manifesto, significa decerto o desfecho, mas o segundo, que dá sua ressonância especial a ambas as palavras, significa a guerra em sua totalidade, indica como o seu desfecho pode alterar seu modo de existência para nós. Esse segundo sentido diz: o vencedor conserva a guerra, o derrotado deixa de possuí-la; o vencedor a incorpora a seu patrimônio, transforma-a em coisa sua, 
o vencido não a tem mais, é obrigado a viver sem ela. $\mathrm{E}$ não somente a guerra em geral, mas todas as suas peripécias, cada uma das suas jogadas de xadrez, inclusive as mais sutis, cada uma das suas escaramuças, mesmo as menos visíveis. Ganhar ou perder uma guerra, segundo a lógica da linguagem, é algo que penetra tão profundamente em nossa existência que nos torna, para sempre mais ricos ou mais pobres em quadros, imagens, invenções. (BENJAMIN, 1994, p. 65).

O pensamento benjaminiano evidencia o quanto a guerra é absorvida socialmente e qual seu poder de transformação. A guerra, vista por essa ótica, produz imagens, forma metáforas, cria uma imagem simbólica que a torna possível. Ao construir atores e cenas, produz um teatro de discursos que envolve a população, convidada a encenar nesse espetáculo chamado guerra.

Susan Sotang, filósofa norte-americana, afirma que a guerra produz metáforas sociais. Nesse sentido, a visibilidade sobre a guerra, a relevância que esta apresenta, liga-se ao seu modo de construção, isto é, como ela será apresentada pelos meios de comunicação. Na segunda estrofe de seu poema, Drummond declara que "Os telegramas de Moscou repetem Homero./ mas Homero é velho. Os telegramas cantam um mundo novo”, evidenciando como essa construção passa da nota jornalística à poesia e pondo em relevo o inevitável vínculo entre ambos. Recorrendo à figura heroica de Homero, os telegramas equiparam a façanha dos soviéticos, que resistiram à ofensiva alemã, aos feitos eternizados na Ilíada e na Odisseia, peças clássicas da epopeia ocidental.

Reorganizando conscientemente essa metáfora, Drummond observa que, o mundo novo, marcado pela guerra e pela dissolução, já não pode cantar como Homero: a forma que se insurge é a do telegrama, que, em seu poder de síntese e sua necessária brevidade retém a pressa e o susto da existência, no mundo industrializado.

Num movimento de versos e imagens, o poeta modernista converte a guerra política em guerra contra as velhas formas de 
dizer e de ver. O poema "Carta a Stalingrado" estabelece-se, assim, como mais que um libelo a favor da vitória dos soviéticos, mas como o manifesto de esperança em uma nova sociedade e, portanto, de uma nova literatura. Inegavelmente, percebe-se que a guerra ataca a sensibilidade tanto daquele que a vive como daquele que a segue, como expectador, por meio dos meios de comunicação.

Segundo a teoria de Sotang, o cotidiano de crueldades, mortes, destruição faz com que o espectador sinta-se "diante da dor dos outros", o que concorrerá com a paulatina banalização dos sentimentos. A guerra, tal como a vemos apresentada nos confrontos ocorridos neste início de século XXI, transformou-se em um espetáculo de imagens, em que a morte e a dor perdem sua força significativa. Sob esse aspecto, cumpre salientar o papel exercido pela literatura que, alimentando-se do fato jornalístico, interpreta-o em suas singularidades, nunca se afastando de seu papel de testemunho e de força expressiva.

A cidade de Stalingrado, no poema drummondiano, não se traduz pelas ruas ou monumentos; personificada, ela representa o sopro vital, capaz de ainda insuflar vigor e resistência ao mundo e ao verbo poético. Metonimicamente é a cidade que traduz a determinação de resistir, como o poeta ao mundo. Seu nome vislumbra-se como "ouro oculto" nos jornais, assim como os versos, cuja força emerge do seu poder de corte e síntese. Se politicamente, vislumbra-se outra organização social possível, há tmbém, no poema, uma consciência de que, para a matéria poética, a motivação e o suporte são outros: "Em teu chão calcinado onde apodrecem cadáveres/a grande Cidade de amanhã erguerá a sua Ordem.".

Davi Arrigucci, 2002, tratando especialmente dos poemas de Sentimento do mundo e A rosa do povo, publicados em 1940 e 1945, respectivamente, analisa a existência de uma perspectiva crítica nas relações entre história e poesia que perpassa toda a obra de Drummond: 
Desde o início, o conteúdo de verdade da poesia de Drummond, como em toda grande poesia, é histórico até o mais fundo e não se separa do problema de sua configuração formal ou da consciência do fazer que sempre o acompanha. E não é histórico porque reproduza fatos históricos, que podem até eventualmente estar referidos ou aludidos nos poemas - "O tempo é a minha matéria, o tempo presente, os homens presentes, a vida presente"-, mas porque revela uma consciência verídica da experiência histórica entranhada profundamente na subjetividade e na própria forma poética que lhe deu expressão. (ARRIGUCCI, 2002, p.102-103).

De fato, essa subjetividade peculiar, cuja luta está em encontrar a justa forma poética, com sua medida ideal, compreende a luta do poeta mineiro em elidir homem e objeto, sua lírica e o movimento histórico de seu tempo.

$\mathrm{Na}$ notícia de jornal, a guerra, para ultrapassar sua esfera imediata e tornar-se objeto de atenção internacional, precisa ser evidenciada como espécie de exceção entre as guerras e representar algo mais do que o choque de interesses dos beligerantes envolvidos. Tornada símbolo pelos jornais, a guerra produz metáforas que gera retratos sociais originários do conflito. A sociedade encarrega-se de representar os vencedores e os vencidos. Os vencedores podem utilizar a guerra em proveito de seus interesses; os vencidos tendem a esquecê-la, mesmo conservando em seu território uma guerra que não mais lhes pertence. Tais constatações podem ser facilmente assimiláveis quando se pensa, por exemplo, na guerra americana deflagrada contra o Iraque, sob o pretexto de se acabar com a ditadura iraquiana e salvar o mundo do ataque de suas armas químicas. Finda a guerra, e contestada a hipótese das armas químicas, que, afinal, nunca foram encontradas, prevalece a história contada pela voz do vencedor.

$\mathrm{Na}$ imagem da Stalingrado que resiste, Drummond opõe características humanas e verbos de ação. Ao apresentá-la em 
frangalhos, fragmentada e ferida, o poeta apela ao sentimento do leitor, forçando-o a visualizar a cidade-corpo combalida, mas corajosa. Essa pode ser a imagem que melhor traduz os esforços de sobrevivência do homem, nos grandes centros. A cidade parece construir-se de acordo com uma disciplina da guerra. Os homens lutam contra o tempo, que lhes foge; as pessoas se engalfinham por um lugar nas filas, nos assentos dos metrôs e dos ônibus; os marginais deflagram uma luta diária contra uma sociedade cercada pela apatia; a sociedade reage à luta dos que estão a sua margem ampliando seus sistemas de defesa e construindo muros mais resistentes. A guerra cotidiana parece diluir, incessantemente, a nossa humanidade. Mas a poesia pode nos salvar, como é possível perceber no apelo cheio de esperança que Drummond lança em seu verbo poético.

Trata-se da poesia que resiste heroicamente, como Stalingrado. Os versos tentam emergir das ruínas, tal como a cidade combalida. Neles se leem a inexatidão e a perplexidade dos novos tempos, que a rima não poderia resolver. O cantar poético nega Homero e os cantos heroicos, pois a vida é difícil, dura e imprecisa como a cidade destruída. Sobretudo, a cidade que emerge das ruínas lembra o esfacelamento e o caráter provisório da vida moderna, que a voz do poeta tenta traduzir. A poesia do seu tempo é saída de uma linhagem de guerra e destruição, compõem-se da ferocidade de viver e encontrar algum sentido nas ações fragmentadas. Do meio, do centro, emerge aquela velha angústia drummondiana, a de tentar reter o tempo, perpetuar o sentido das coisas e dos sentimentos, embora a consciência de sua perenidade seja absoluta.

Nesse aspecto, a poesia que "fugiu dos livros e agora está nos jornais" parece ser o grande tom do poeta modernista, este que defende uma poética que fez do tempo presente e da vida presente sua matéria. Lê-se, nos seus versos, a ansiedade de escapar das esferas acadêmicas e a necessidade de frequentar o cotidiano do povo, bem como essa ciência dolorosa de que tudo é 
efêmero e urgente, como os fatos noticiados em jornal, mas contra quem a poesia, por sua própria natureza de arte, tenta resistir. A matéria é passageira, mas a forma que a retém ou sustenta permanece.

Inútil não pensar sobre os efeitos da guerra; a guerra modifica os homens e modifica as sociedades. Uma guerra sempre denotará um mundo em crise, uma ausência de soluções e uma proposta a outra ordem, independente do grau de crueldade que empregue em seu esforço de vitória. Uma guerra pode também criar dores nunca superadas e cicatrizes no modo de viver de uma geração, de uma época, de um tempo específico. $O$ mundo nunca foi o mesmo depois da Segunda Guerra Mundial, e Drummond, com sua pena atenta, vê, nos escombros deixados, a imagem da nova organização social e da nova literatura, em que acredita.

"Carta a Stalingrado" pode contar-nos apenas de uma cidade sitiada que, mesmo diante do poderio beligerante de seu invasor, consegue derrotá-lo. Mas a metáfora que emerge de seus versos é maior - "a vida em ti é prodigiosa e pulula como insetos ao sol, ó minha louca Stalingrado!". Mesmo depois da guerra, esses insetos, e suas implicações, lutam pelo sol, em nossa sociedade.

\section{REFERÊNCIAS}

ACHCAR, F. Carlos Drummond de Andrade. São Paulo: Publifolha, 2000. p. 12-13.

ANDRADE, C. D. de. A rosa do povo. Rio de Janeiro: Record, 1997.

ARRIGUCCI, D. O guardador de segredos. São Paulo: Companhia das Letras, 2010. p. 15-25.

ARRIGUCCI, D. Coração partido - uma análise da poesia reflexiva de Drummond. São Paulo: Cosac \& Naify, 2002. p. 102-103.

BENJAMIN, W. Teorias do Fascismo Alemão. In: Obras Escolbidas: Magia e técnica, arte e política: ensaios sobre literatura e história da cultura. Trad. Sérgio Paulo Ravanet. 7. ed. São Paulo: Brasiliense, 1994. p. 65. 
BOSI, A. O ser e o tempo da poesia. São Paulo: Companhia das Letras, 2000. p. 10.

BOSI, A. História Concisa da Literatura Brasileira. 4. ed. São Paulo: Cultrix, 2000. p. 441.

FAUSTO, B. Getúlio Vargas: o poder e o sorriso. São Paulo: Companhia das Letras, 2006.

SONTAG, S. Diante da dor dos outros. São Paulo: Companhia das Letras, 2003. p. 33.

Recebido para publicação em 29 de dezembro de 2012. Aprovado em 7 de maio de 2013. 